\title{
The Determination of Available Phosphorus in Soil: A Quick and Simple Method
}

\author{
I. S. A. Koralage ${ }^{2}$, P. Weerasinghe ${ }^{2}$, N. R. N. Silva ${ }^{2}$ and \\ C. S. De Silva ${ }^{1}$ \\ ${ }^{1}$ Department of Agricultural and Plantation Engineering, The Open \\ University of Sri Lanka \\ ${ }^{2}$ Horticultural Crop Research and Development Institute, Gannoruwa, Sri \\ Lanka
}

\begin{abstract}
The study attempts to develop a quick and a simple phosphorus (P) testing method to get the idea about the $\mathrm{P}$ level in the soil for farmers so that they may be able to decide the amount of phosphorus fertilizer for their cultivation. Four new phosphorus extraction methods were used which are Mogen's method, distilled water method, basify distilled water method and acetic acid method. Extracted phosphorus was measured by Murphy and Riley colorimetric method and correlated each method with the Olsen method because Olsen method has grown in stature and reputation over the years as the best and cheapest method suitable for mild acidic to base soils. The significant correlations $\left(\mathrm{r}^{2}\right)$ of Mogen method, distilled water extraction method, basify distilled water extraction method and acetic acid extraction methods with Olsen method were $0.734,0.585,0.654$, and 0.854 respectively. The acetic acid phosphorus extraction method which has the best correlation with the Olsen method was further simplified and its significant correlation with the Olsen method was 0.855. Simplified acetic acid method was the best simple P extraction method in the field level test and the extracted $\mathrm{P}$ can be measured using the newly introduced color chart in this study. Subsequently a field soil testing kit was developed based on the results for the farmers to test the soil phosphorus content by themselves before the cultivation and decide on phosphorus fertilizer application.
\end{abstract}

${ }^{1}$ Correspondence should be addressed to Prof. C. S. De Silva, Department of Agricultural and Plantation Engineering, Faculty of Engineering Technology, The Open University of Sri Lanka, Nawala, Nugegoda, (Email: csdes@ou.ac.lk.) 
Keywords: Soil phosphorus, testing, fertilizer application, Olsen's method, Murphy and Riley method

\section{Introduction}

Phosphorus is a major essential plant macro nutrient which is needed for plant growth and development. Extensive cultivation of vegetables and other crops along with natural hazards cause for depletion of natural phosphate content in the soil. Therefore, phosphate fertilizers have been used to overcome this depletion and to enrich the respective soil.

Different types of crops may differ in their fertilize requirements. Therefore, fertilizer recommendations are available for crop to crop which were recommended by the Department of Agriculture for each crop as per to the nutrient consumption of each crop. But the majority of Sri Lankan farmers apply higher than the recommended amounts of such fertilizer aiming for higher commercial benefits through a well growth. Due to this over application, phosphorus in some forms accumulates in intensive cropping lands which cannot be taken up by the plants, thus, creating several environmental problems. For soils, P fertilizer responsible in accumulating heavy metals in intensive cropping lands (Allaway, 1971) and for water ways, Phosphorous that is washed into waterways may lead to eutrophication, which has serious health problems for both human and animals (Rohlich et al., 1980).

Knowing the level of available $\mathrm{P}$ in farmland is very important to manage the phosphorus supply by soils. Consequently, the most important tool for such is a soil test which could be used for $\mathrm{P}$ recommendations for the crop grown. Making site-specific fertilizer recommendation will no doubt result in economical and environmental benefits.

Soil analytical laboratories of Government Department of Agriculture in Sri Lanka provide the service of soil phosphorus testing in general which widely used Olsen's method (Olsen et al, 1954) to extract the available soil P from soils. Olsen's method is most accurate method for soils in the range of mild acidic to basic $\mathrm{pH}$. Since farmers have to travel far and handover their soil samples to soil testing laboratories and to pay, they do not tend to get their soils analyzed before cultivation. If there would have been a rapid and an easy method for testing phosphorus in the soil outside of a laboratory, so that farmers could test the soil, by even with the assistance of 
Agricultural Instructors, such may iron out the constraints faced by them.

The simple and rapid methods have several benefits such as reducing the time taken, skills, equipments and chemicals etc. Such may in turn create more benefits for farmers through motivating them to do soil testing without waiting for the result and to get the $\mathrm{P}$ level in their soil they cultivate just before the starting the cultivation enabling them to apply proper dose of $\mathrm{P}$ fertilizer. Therefore, this study was undertaken to introduce a new, simple and low cost soil phosphorus testing method which can determine soil available phosphorus in-situ.

The fundamental goal of soil $\mathrm{P}$ testing has always been to identify the "optimum" P concentration required for plant growth. The need for additional fertilization or manuring, and the economic return on an investment in $\mathrm{P}$ fertilizer, could then be predicted. Sims et al., (1998) stated that other objectives of soil P testing have been to: (i) "index" the P supplying capacity of soils, thus estimating the time before fertilization would again be required; (ii) group soils, in terms of the likelihood of an economic response to $\mathrm{P}$, based on their physical and chemical properties; and, (iii) most recently, to identify when soils are sufficiently excessive in $\mathrm{P}$ to contribute to non point source pollution of surface and groundwater. Bray (1948) proposed that an acceptable agronomic soil $\mathrm{P}$ test should have the following characteristics:

- The soil test should extract all or a proportionate amount of the plant-available $\mathrm{P}$ forms in soils with differing chemical and mineralogical properties.

- $\quad$ The soil test should be accurate and rapid.

- $\quad$ The P extracted by the soil test should be well correlated with plant $\mathrm{P}$ concentration, plant growth, and the response of the plant to added $\mathrm{P}$ in forms of fertilizers or manure.

- The soil test should accurately detect differences in soil P concentrations caused by previous fertilization or manuring.

Soil testing is a useful tool in making site-specific fertilizer recommendation, will no doubt result in economic and environmental benefits. During the past forty years, testing procedures have been improved remarkably with greater emphasis on precision and efficiency (Silva et al., 2007). 
Several soil tests are used to assess phosphorus availability. The Ammonium bicarbonate - Diethelenetriaminepentaacetic acid $\left(\mathrm{NH}_{4} \mathrm{HCO}_{3}\right.$-DTPA) soil test for the simultaneous determinations of available N, P and micronutrients was developed by Soltanpour and Schwab (1977).

Sodium bicarbonate $\left(\mathrm{NaHCO}_{3}\right)$ soil test for phosphorus has been used extensively. The experience in Britain is that extraction of soil with sodium bicarbonate is generally the best method on which to base advice to farmers on fertilizer used. In this method, $5 \mathrm{~cm}^{3}$ soil $(<2 \mathrm{~mm})$ is extracted for 30 minutes with $100 \mathrm{~cm}^{3} 0.5 \mathrm{NaHCO}_{3}$ solution ( $\mathrm{pH}$ adjusted to 8.5). After filtration the phosphate concentration of the solution is measured calorimetrically and the result is expressed as mg per liter of soil (Olsen et al., 1954).

Extractable Phosphorus in dilute solutions as $\mathrm{CaCl}_{2}$, saturation extracts, and displaced soil solutions are useful indices of phosphorus availability (Olsen and Sommers, 1982; Soltanpour and Schwab (1977). However use of a $\mathrm{CaCl}_{2}$ solution is easier than the use of displaced soil solution or saturation extract to measure phosphorus availability. The $\mathrm{CaCl}_{2}$ extract approximates the composition of the soil solution (Khasawneh et al., 1967).

Researchers have used Ethelenetriaminepentaacetic acid (EDTA) or its salts for evaluating the nutrient status of soils. A neutral solution of $0.02 \mathrm{M} \mathrm{Na} \mathrm{N}_{2} \mathrm{EDTA}$ extracted solution has a high correlation between $\mathrm{Na}_{2}$-EDTA extractable soil P and plant P (Ahmad and Islam, 1975).

Measurement of the $\mathrm{P}$ amount transferred to the solution phase during the extraction can be done colorimetrically or by using inductively coupled plasma (ICP) spectroscopy. The ICP determination gives the total amount of $\mathrm{P}$ in solution and thus, to analyse phosphate, requires the use of colorimetric methods. The most commonly used molybdenum blue method, developed by Murphy and Riley (1962), is based on the reaction of $\mathrm{PO}_{4}-\mathrm{P}$ with molybdate to form a blue compound at low $\mathrm{pH}$ in reducing conditions. The intensity of the color corresponds to the concentration in the solution and can be measured with a spectrophotometer. The concentration of total phosphorus (TP) in the solution can be determined colorimetrically after digestion of the sample, e.g. in autoclave with oxidizing chemical, such as persulfate $\left(\mathrm{K}_{2} \mathrm{~S}_{2} \mathrm{O}_{8}\right)$. 
In molybdenum blue method, the colored compound is formed with free $\mathrm{PO}_{4}-\mathrm{P}$ and the resulting concentration is thought to represent the dissolved phosphate. However, problems involved in measuring dissolved phosphate with the molybdenum blue method were acknowledged already in 1968 when Rigler hypothesized that the molybdenum blue methods give values for dissolved $\mathrm{PO}_{4}-\mathrm{P}$ that are too high because of the hydrolysis of $\mathrm{PO}$ taking place in the acidic conditions required for molybdenum blue complex formation. Turner et al. (2005), however, concluded that the error caused by acid hydrolysis is likely to be negligible in quantitative analysis and, in fact, reported molybdenum blue method to give too low values for $\mathrm{PO}_{4}-\mathrm{P}$ in solution because of $\mathrm{PO}_{4}-\mathrm{P}$ associated with organic molecules may precipitate in acidic conditions during the color formation. Yet another source of error in the analytical procedure for measuring the phosphate with the molybdenum blue method results from the fact that the intensity of the color reflects only the amount of phosphate phosphorus $\left(\mathrm{PO}_{4}-\mathrm{P}\right)$ in the sample leaving the other phosphate compounds, such as poly-pyrophosphates, undetected (Turner et al., 2005). This kind of underestimation of phosphate concentration by molybdenum blue method can be demonstrated by using ${ }^{31} \mathrm{P}-\mathrm{NMR}$ spectroscopy (Turner et al., 2006).

There are several rapid soil testing kits are used all over the world. Most of the field soil kits available based on test strips, visual comparator and photometer kits. These kits are very expensive and the minimum cost will be around 10000 rupees. This will be expensive for Sri Lankan farmers. Therefore, this study intend to develop a simple and rapid soil phosphate testing kit to be provided for the farmers free of charge or at an affordable price. Then the farmers can determine the $\mathrm{P}$ concentration in soils in order to decide the $\mathrm{P}$ manuring.

\section{Materials and Methods}

Soil samples received under the soil testing program of Agricultural Chemistry division at the Horticultural Crops Research and Development Institute, Gannoruwa were used for this study. Seventy five samples were included for the study. Phosphorus content in each sample was determined using the Olsen method to extract the available soil phosphorus (Olsen et al., 1954) and Murphy and Riley method (1962) was used to measure the extracted phosphorus amount. Olsen method was used because the $\mathrm{pH}$ of soil samples collected were in the range of 4.4 to 7.1 represents the mild acidic to basic condition. Olsen method was the appropriate and low cost 
method widely accepted over the years for such mild acidic to basic soils.

\section{Development of a New Method for Measure the Soil Phosphorus}

As the available phosphorus testing methods, development of a simple and rapid method to quantify the soil available phosphorus was carried out with two steps; namely 1. Extract the available phosphorus in soil and 2. Measure the extracted phosphate. The selected soil samples were used to do this study.

Available Phosphorous in each sample was extracted using four different extraction methods

\section{i. Morgan's method.}

$0.72 \mathrm{~N}$ Sodium acetate $+0.52 \mathrm{~N}$ Acetic acid solution was used as the extractant in this method.

ii. Basify distilled water method.

Distilled water basified using $\mathrm{NaOH}$ and $\mathrm{pH}$ adjusted to 8.5 was used as the extractant.

\section{iii. Distilled water only method.}

The extractant was the distilled water $(\mathrm{pH} 4.8)$ in this method.

iv. Acetic Acid method.

$2.5 \%$ acetic acid solution was used as the extractant.

The same soil sample was used to measure the amount of phosphorus extracted by 4 different extraction methods. For each method, $5.0 \mathrm{~g}$ of soil and pinch of $\mathrm{P}$ free charcoal were mixed with 50 $\mathrm{ml}$ of each extractant in a dry and clean plastic bottle. The solution was shaked manually for 2 minutes and filtered using No. 5 Whatman filter paper. The extracted soil phosphorus was measured by Murphy and Riley (1962) method.

Phosphorus concentrations obtained from each extraction method were compared by correlating with phosphate obtained by the Olsen's method. 


\section{Further Simplification of the Best Correlating Method}

Acetic acid extraction method was further simplified. The selected 75 soil samples were also used for this method. $5.0 \mathrm{~g}$ of soil sample was added in to a clean and dry plastic battle. $50 \mathrm{ml}$ of $2.5 \%$ acetic acid solution was also added and extracted for 2 minutes mixed with hand, kept for about 3 hours (Figure 1) until the supernatant was separated. The supernatant was analyzed for phosphorus using "Murphy and Riley colorimetric method" (1962). In this method neither phosphorus free charcoal added nor filter paper was used to filter the solution which reduces the cost further to develop the soil testing kit in this study.

The experience in Britain is that extraction of soil with Olsen's method is generally the best method on which the advice to farmers on fertilizer application was based. Presently the Olsen's extraction method is used to measure the available phosphorus in soil which estimates the relative availability of ortho-phosphate $\left(\mathrm{PO}_{4}-\mathrm{P}\right)$ using $0.5 \mathrm{~N} \mathrm{NaHCO}_{3}$ adjusted to $\mathrm{pH} 8.50$ (Olsen et al., 1954). Further the soil samples collected in this study has the $\mathrm{pH}$ range of mild acidic to basic ( $\mathrm{pH}$ 4.4-7.2) and the Oslen method is the best suited method for such soils. Therefore, all the extraction methods were statistically compared by correlating with the Olsen method.

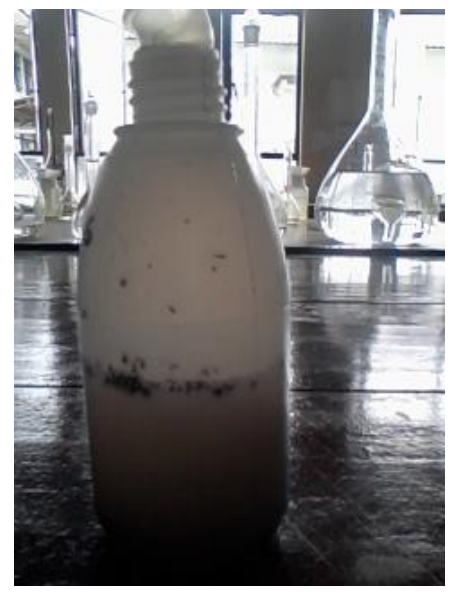

(a)

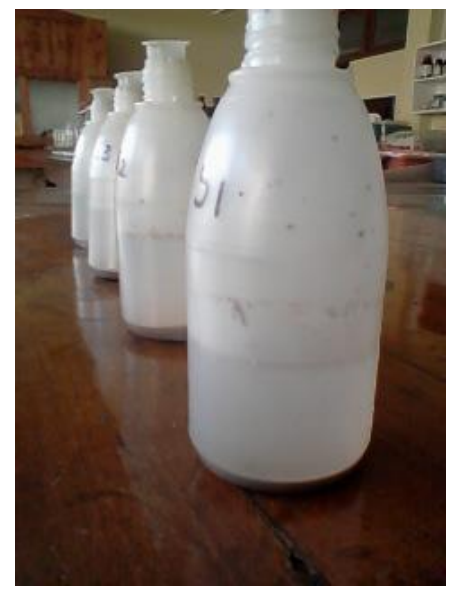

(b)

Figure 1. (a) The mixed soil solution in simplify acetic acid method.

(b) The soil solution after 3 hours with the supernatant 


\section{Results and Discussion}

\section{Selection of the Best Phosphorus Extraction method}

Four different extraction methods, Morgan's extraction method, distilled water and basify distilled water extraction methods and acetic acid extraction method were used to extract available phosphorous in selected soil samples. The soil phosphorus contents extracted using the four different extraction methods were measured using the Murphy and Riley colorimetric method and the results were correlated with the Olsen's method. The correlations were taken from the Regression analysis, thereby selected the best extraction method which has highest correlation with Olsen's method.

Figure 2 shows that the corelation of each extraction method; distilled water and basify distilled water methods, Morgan's method and acetic acid method respectively. The linear relationship is expressed as $r^{2}$. The $r^{2}$ values of distilled water only method, basify distilled water method; Morgan's method, and acetic acid method were $0.589,0.653,0.734$ and 0.853 respectively. According to the study, all the $\mathrm{r}^{2}$ values were in the range between $0.5-1.0$, hence, all the new methods have ideal correlations with Olsen's method.

Distilled water was used in the study as an extractant as per to its several advantages. Distilled water in common is easily available, relatively inexpensive; shelf life is longer in optimum conditions, ease of handling in simple field level tests. But, $\mathrm{r}^{2}$ value for distilled water only method with Olsen's method was 0.589 which was the lowest correlation among other 4 extraction methods following to Basify distilled water method. Therefore, this method disqualifies in extracting available phosphorous in soil.

The $\mathrm{r}^{2}$ value of Morgan's method used in this study was 0.734 and it was closed to the $r^{2}$ value (0.74) reported by Foy et al. (1997). Foy et al., have compared Olsen and Morgan soil phosphorus tests using 199 soil samples using electrical shaker to mix the soil suspensions and in our study soil suspensions were mixed by hand. The $\mathrm{r}^{2}$ difference between Foy's study and the present study was 0.006. It shows there has no significant difference between hand mixing method and electric shaking for mixing soil suspension. In this study hand mixing method was used for all the modified extraction methods as the particular extraction method should be simple and easy to do at field level. 


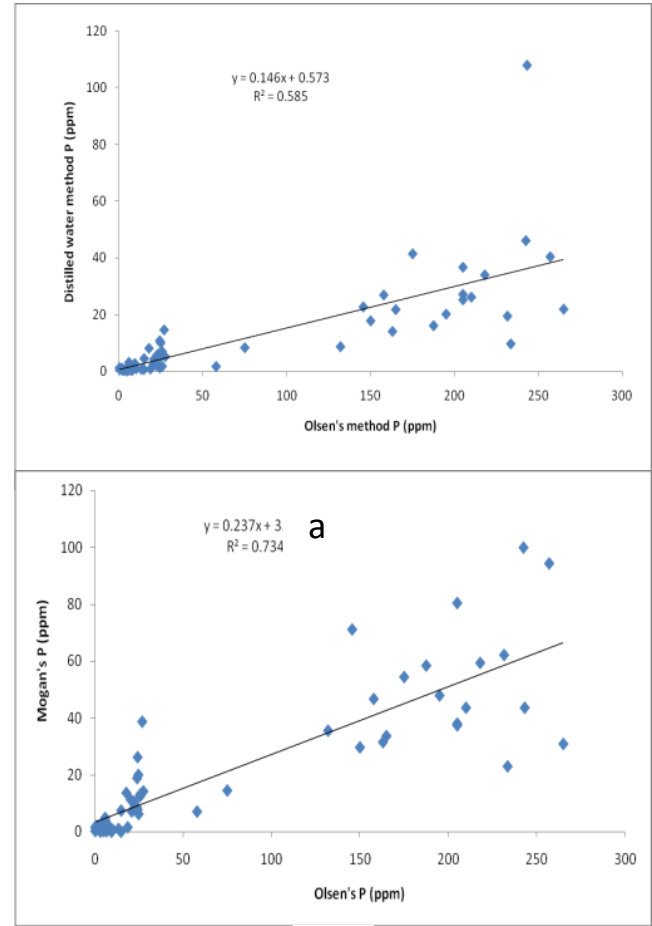

C

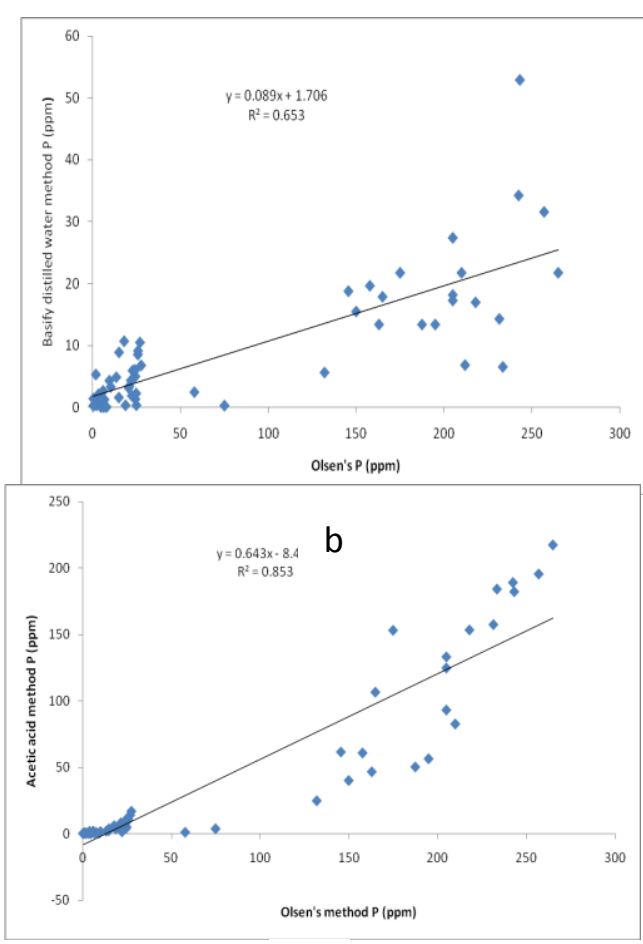

d

Figure 2: $\quad$ (a) Regression analysis of distilled water method and Olsen's method

(b) Regression analysis of basify distilled water method and Olsen's method

(c) Regression analysis of Morgan's method and Olsen's method

(d) Regression analysis of acetic acid method and Olsen's method

Acetic acid method consists only of $2.5 \%$ Acetic acid solution and no sodium acetate as in Morgan's method. However the $\mathrm{r}^{2}$ value of Acetic acid method was 0.853 , which was the highest correlation with Olsen's method.

According to the results obtained in the study, correlation order can be expressed as; Acetic acid method > Morgan's method > Basify distilled water method $>$ Distilled water method. Hence, the Acetic 
acid method was selected as the best extraction method to extract available phosphorous in soils.

\section{Simplification of the Best Extraction Method}

The Acetic acid method was further simplified to fine tune the results. The supernatant of the soil suspension was used to measure the extracted phosphorus without using the filtrate. It saves the cost of filter papers too in the simplified method. Figure 3 shows the Regression analysis of simplify acetic acid methods with Olsen's method.

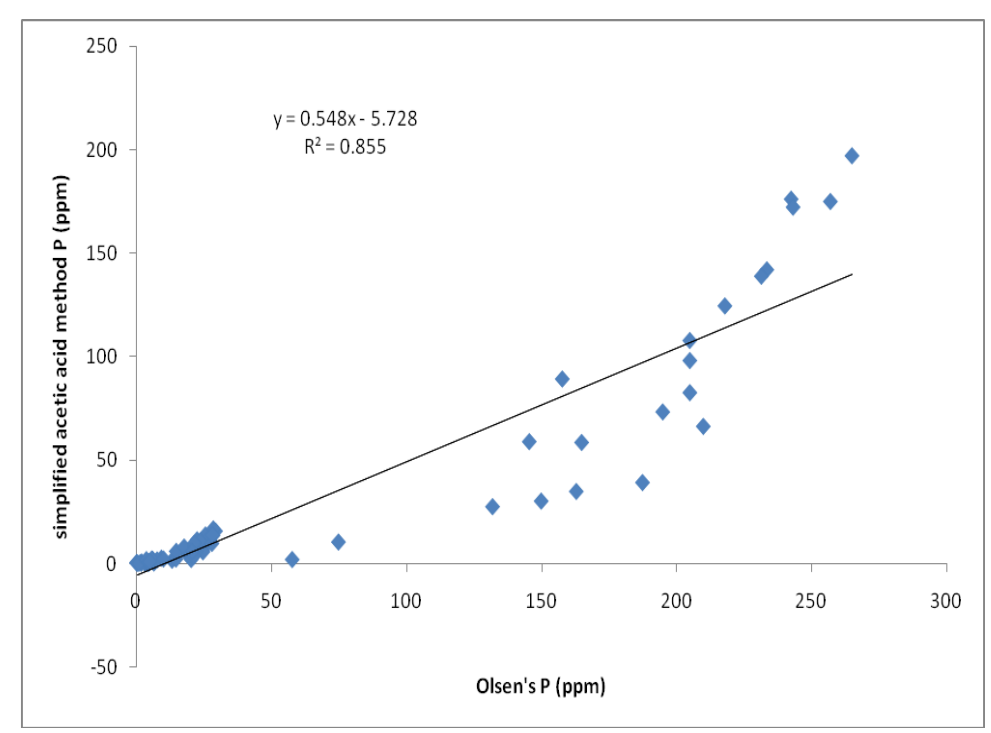

Figure 3. Regression analysis of Olsen's method and simplify Acetic Acid method

Regression analysis of figure 3 shows a significant correlation between Olsen's method and simplified acetic acid method $\left(\mathrm{R}^{2}=\right.$ 0.855). Therefore the simplified acetic acid method was selected as the simplest soil phosphorus extraction method which can be applied for phosphorus test in field level.

\section{Development of Phosphorus Identification Color Chart}

Murphy and Riley colorimetric method was used to determine the phosphorus amount in extracted solution. Color developing regent was added in to the soil filtrate before measure the phosphorus amount. The molybdate ions in the color developing regent ordinate with phosphorus in the soil extract as the central coordinating atom 
forming heteropoly complexes (Murphy and Riley, 1962). This complex was blue in color. The intensity of the blue color was increasing with the phosphorus ions in the extract. Therefore according to the blue color intensity of the repaired phosphorus extract the phosphorus level of it can be determined.

A color chart was prepared for the identification of the phosphorus level in the extraction through the blue color intensity. Simplified acetic acid method phosphorus content of low phosphorus soil, medium phosphorus soil and high phosphorus soil were calculated to make the color chart.

Olsen's phosphorus content of soil is expressed as ppm in table 1

Table 1. Olsen's phosphorus content of soil

\begin{tabular}{|l|c|}
\hline & Available P (ppm) \\
\hline Extremely high & $>30$ \\
\hline High & $22.5-30$ \\
\hline Medium & $15-22.5$ \\
\hline Low & $<15$ \\
\hline
\end{tabular}

According to the equation of regression graph of Olsen's method and simplified Acetic acid method (Figure 3) simplified acetic acid method phosphorus content of soil was calculated and presented in Table 2 .

To get the blue color intensity of $2.5 \mathrm{ppm}, 6.6 \mathrm{ppm}$ and $10.7 \mathrm{ppm} \mathrm{P}$ solution, sample series was prepared using $5 \mathrm{ppm}$ phosphorus solution, color developing regent and distilled water. The phosphorus contents of prepared samples were measured using the spectrophotometer at the wave length of $880 \mathrm{~nm}$. Samples were selected the which had $2.5 \mathrm{ppm}, 6.6 \mathrm{ppm}$ and $10.7 \mathrm{ppm}$ phosphorus (Figure 4) and their blue color intensities were used to prepare color chart. The color chart consists of 3 different intensity of blue color (Figure 5). 
Table 2. Simplified acetic acid method phosphorus content of soil

\begin{tabular}{|l|c|}
\hline & Available P (ppm) \\
\hline Extremely high & $>10.7$ \\
\hline High & $6.6-10.7$ \\
\hline Medium & $2.5-6.6$ \\
\hline Low & $<2.5$ \\
\hline
\end{tabular}

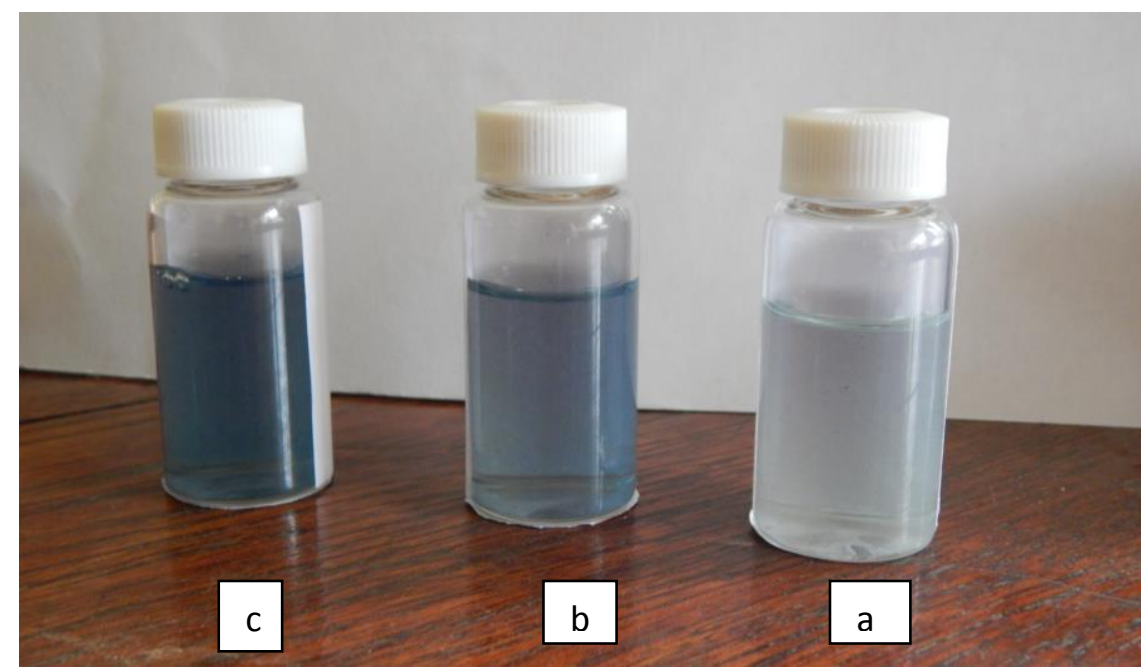

Figure 4. $\quad 2.5 \mathrm{ppm}(\mathrm{a}), 6.6 \mathrm{ppm}(\mathrm{b})$ and $10.7 \mathrm{ppm}(\mathrm{c})$ phosphorus samples 


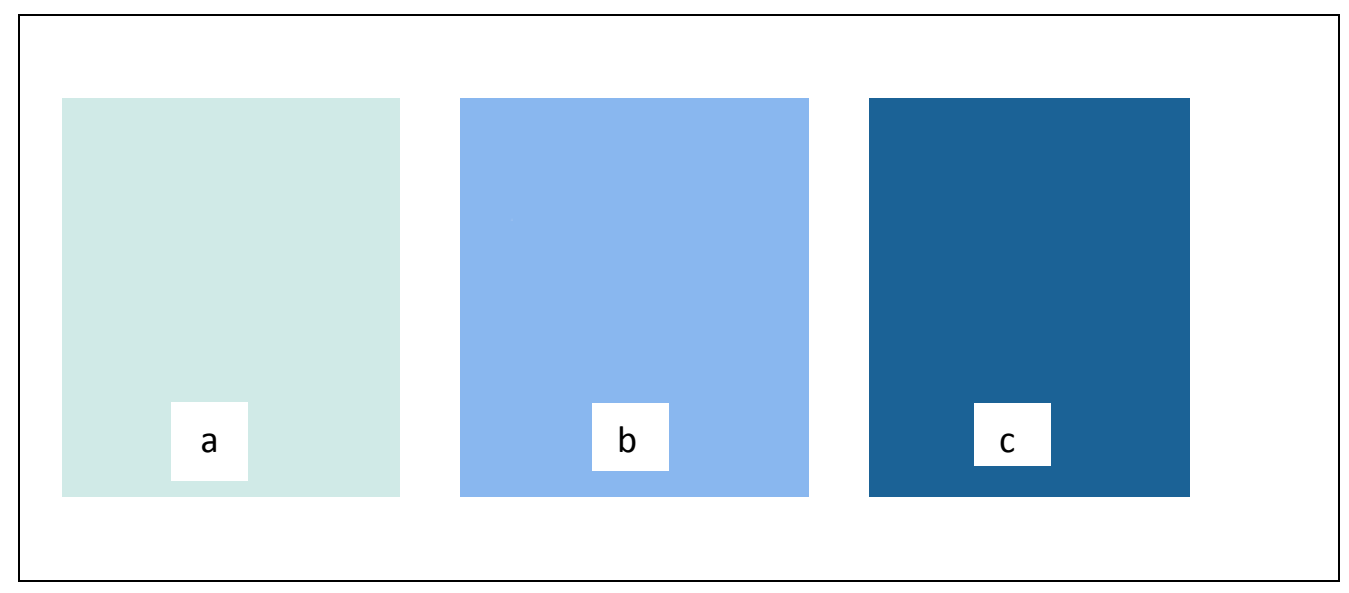

\section{Colour}

$>$ ( c )

Between ( b ) and ( c ) color

Between ( a ) and ( b ) color $<(\mathrm{a})$

\section{P content}

Extremely high P soil

High P soil

Medium P soil

Low P soil

The color chart consists of three different intensity of blue color. A color developed sample's phosphorus level can be determined using this color chart.

\section{Newly Developed Soil Phosphorus Testing Tool Kit}

This tool kit was developed based on the findings of this study. The new soil available phosphorus test can be applied in the field with this tool kit. The tool kit includes distilled water, 2.5\% acetic acid solution, mixed regent, ascorbic acid, a clean glass bottles, the soil $\mathrm{P}$ color chart and also the note of the procedure of new phosphorus testing method. Figure 6 shows a model of a simple tool kit developed in this study. This tool kit is very easy to transport and handle and not cost more than Rs 200. However, these kits could be given to farmers free of charge or at an affordable price. The soils $\mathrm{P}$ can be measured according to the procedure introduced by this 
study by using this tool kit by the farmers themselves and decide the phosphate fertilizer application.
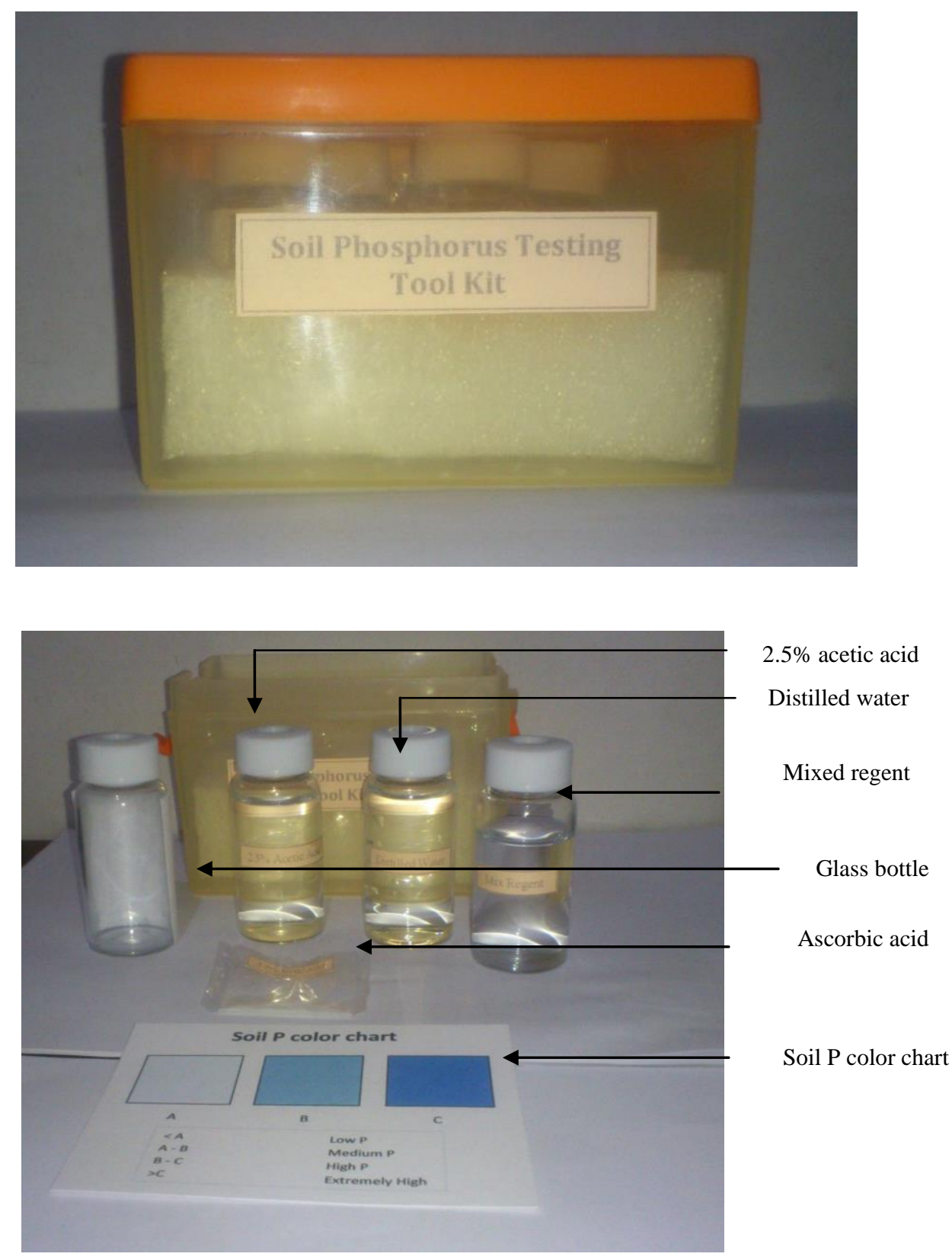

Figure 6. Newly developed soil available P testing tool kit 
${ }^{* *}$ color developing regent cannot be stored long period of time. Mix reagent and ascorbic acid can be stored separately and can be prepared the color developing regent by mix those together few minutes before using.

\section{The Procedure of New Phosphorus Testing Method}

1. Take a soil sample as the recommended procedure

2. Remove the large soil particles and foreign materials from the sample.

3. Take $5 \mathrm{~g}$ of soil and put it in to a clean and dry plastic bottle.

4. Add $50 \mathrm{ml}$ of $2.5 \%$ acetic acid solution in to the bottle.

5. Mix the solution two minutes manually.

6. Keep the solution for about three hours until the supernatant separates.

7. Put $5 \mathrm{ml}$ of supernatant in to a transparent glass bottle.

8. Add $5 \mathrm{ml}$ of color developing regent $\mathrm{t}^{* *}$ in to it.

9. Add $5 \mathrm{ml}$ of distilled water.

10. Mix the solution well and keep it for about 15 for minutes to develop the blue color.

11. Measure the blue color intensity using the color chart. Thereby identify the phosphorus level in the soil.

To get the accurate level of phosphorus, soil sample should consist of fine particles and it should be dry. Wet soils samples can be used to test for phosphorus after allow it to dry.

\section{Conclusion}

The simplify acetic acid method which has the best significant correlation with the Olsen's method can be introduced for the determination of available phosphorus. The method developed in this study by reducing the tools and equipments, reducing the extraction time, introducing manual shaking for 2 minutes which is suitable for extract soil phosphorus in the field level test. Not specific equipments need to apply this method. The soil testing kit developed in this study use the commonly available low cost materials which 
can be given for farmers as a tool kit free of charge. The total cost for this developed tool kit is less than Rs 200.

Extraction phosphorus measuring method is very easy. The introduced phosphorus color chart can be handled easily to measure the extracted phosphorus level, after developing the blue color of extracted solution. Therefore even farmers can use this test tool kit to measure the available soil phosphorus in the lands before the cultivation and decide the phosphorous fertilizer application appropriately. This finding will help the farmers to test the available soil phosphorus content without any additional cost accurately and reduce the cost of fertilizer application. Consequently it will reduce soil and groundwater pollution due to over use of phosphorus fertilizer application which is a national need.

\section{References}

Ahmed, B., \& Islam, A. (1975). The use of sodium EDTA as an extraction for determination available phosphorus in soil. Geoderma 14:261-265.

Allaway, W. H. (1971). Feed and food quality in relation to fertilizer use (2nd Edition). In: Fertilizer Technology and Use. R.A. Olson (Editor), 533-566. Soil Science Society of America, Madison.

Bray, R. H. (1948). Correlation of soil tests with crop response to fertilizers and with fertilizer requirement. In H.B. Kitchen (ed.) Diagnostic techniques for soils and crops. Am. Potash Inst., Washington, D. C. p. 53-86.

Foy, R. H., Tunney, H., Carroll M. J., Byrne E., Gately T., Bailey J. S., \& Lennox, S. D. (1997). A comparison of Olsen and Morgan soil phosphorus test results from the cross-border region of Ireland. Irish Journal of Agricultural and Food Research 36: 185-183.

Khasawneh, F. E. \& Adams, F. (1967). Effect on dilution on calcium and potassium contents of soil solutions. Soil sci. soc. Am. Proc. 31:172-176.

Murphy, J. \& Riley. J. R. (1962). A modified single solution method for the determination of phosphorus in natural waters. An. Chem. Acta. 27:31-36. 
Olsen, S. R., Cole, C. V., Watanabe, F. S. \& Dean. L. A. (1954). Estimation of available phosphorus in soils by extraction with $\mathrm{NaHCO}_{3}$, USDA Cir.939. U.S. Washington.

Olsen, S. R., \& Sommers, L. E. (1982). Phosphorus. In A. L. page et al., (ed) Methods of soil analisis, 2nd ed. Agronomy 9:403-430.

Rohlich, G. A. \& O'connor, D. J. (1980). Phosphorus management for the great lakes. Final rep., phosphorus strategies task force, Int. joint commission (IJC). Pollution from land use activities reference group tech. rep. phosphorus management strategies task force, Windsor, Ontario.

Silva, N. R. N., Lathiff, M. A. \& Maraikar, S. (2007). Simple and rapid test method for assessing available N,P,K levels in soil. J. soil sci. Sri Lanka, vol. 19.

Sims, J. T., Simard, R. P. \& Joern, B. C. (1988). Phosphorus loss in agricultural drainage: historical perspective \& current research. Journal of Environmental quality. 27:277-293.

Soltanpour, P. N. \& Schwab, A. P. (1977). A new soil test for simultaneous extraction of macro and micro nutrients in alkaline soils. Commun. Soil Sci. Plant Anal. 8(3):195-207.

Turner, B. L., Cade-Menun, B. J., Condron, L. M. \& Newman, S. (2005). Extraction of soil organic phosphorus. Talanta 66, 294-306.

Turner, B. L., Newman, S. \& Reddy, K. R. (2006). Overestimation of organic phosphorus in wetland soils by alkaline extraction and molybdate colorimetry. Environmental Science and Technology 40, 3349-3354.

Received: 29-1-2015 Revised: 8-5-2015 Accepted: 12-5-2015 